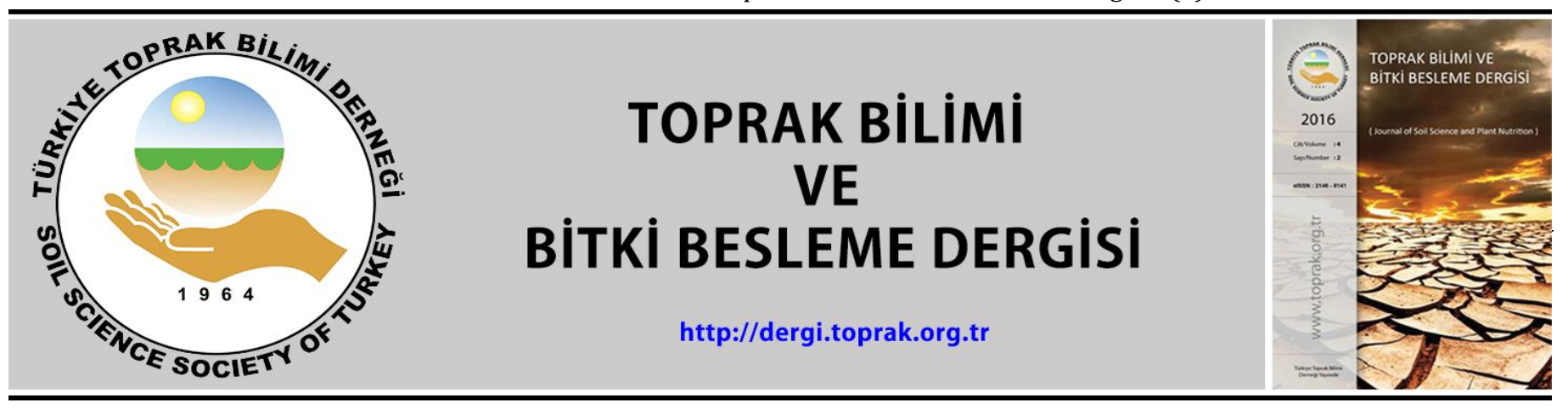

\title{
Toprak kalınlığına bağlı oluşan yükün toprak gerilimine etkisi
}

\section{Coşkun Gülser, İmanverdi Ekberli *}

\author{
Ondokuz Mayıs Üniversitesi, Ziraat Fakültesi, Toprak Bilimi ve Bitki Besleme Bölümü, Samsun
}

\begin{abstract}
Özet
Toprak geriliminin değerlendirilmesi, toprak yönetimi ile ilgili kültürel işlemlerin uygun zamanda yapılması, verimliliğinin artırılması ve toprak yönetimi açısından önem taşımaktadır. Bu çalışmada katı ortamdaki gerilim ve deformasyon; gerilim ve deformasyon arasındaki fonksiyonel ilişki teorik olarak incelenmiștir. Toprak yüzeyindeki yük miktarından kaynaklanan toprak gerilimini değerlendirmek için gerilim ve deformasyon arasındaki zamana bağlı olmayan denklemler kullanılarak analitik bir ifade elde edilmiştir. Elde edilen bu ifadeden toprağın özgül ağırlığına bağlı olarak farklı derinlikler için gerilim değerleri hesaplanmıştır. Toprağın düșey yüzeysel geriliminin özgül ağılık ve toprak derinliği ile doğru orantılı olduğu saptanmıştır. Topraktaki yük miktarı veya toprak derinliğinin artışı, özgül ağırlık artışı ile karşılaştırıldığında toprakta gerilimi daha fazla etkilemektedir. Özgül ağırlık $2.50-2.80 \mathrm{~kg} / \mathrm{m}^{3}$ aralığında değiştiğinde, kumlu bir toprak için Poisson sayısı $(v)$ 'nın ortalama 0.25 olması durumunda, $0.2 \mathrm{~cm}$ toprak derinliği için gerilim $0.0327-0.0366 \mathrm{kPa} ; 5.0 \mathrm{~cm}$ derinliği için $0.8175-0.9156 \mathrm{kPa}$ aralığında değișmektedir. Killi bir toprak için ise, Poisson sayısı 0.40 alındığında, $0.2 \mathrm{~cm}$ toprak derinliğinde gerilim $0.0163-0.0183 \mathrm{kPa} ; 5.0 \mathrm{~cm}$ derinliğinde ise $0.4087-$ $0.4578 \mathrm{kPa}$ aralığında belirlenmiştir.
\end{abstract}

Anahtar Kelimeler: Deformasyon, gerilim, Poisson sayısı, yük, toprak kalınlığı.

\section{Effect of load occurred by soil thickness on soil stress}

\begin{abstract}
Evaluation of soil stress is important to soil management and related cultural processes to be done in appropriate time, and also important to soil fertility and conservation. In this study, stress and deformation in solid media; the functional relation between stress and strain were investigated theoretically. To evaluate the soil stress due to load on soil surface, an analytical statement was obtained using the time-independent equations between stress and deformation. Soil stress values for different soil depths were calculated using soil particle density values in this expression. The vertical surface stress was found to be directly proportional with particle density and soil depth. Increment in soil depth is more effective on soil stress than increment in particle density. When particle density ranged from 2.50 to $2.80 \mathrm{~kg} / \mathrm{m} 3$ and average Poisson number was 0.25 , soil stress values for a sandy soil varied between 0.0327 and $0.0366 \mathrm{kPa}$ in $0.20 \mathrm{~cm}$ soil depth, and between 0.8175 and $0.9156 \mathrm{kPa}$ in $0.50 \mathrm{~cm}$ soil depth. When average Poisson number 0.40 , clay soil stress values varied between 0.0163 and $0.0183 \mathrm{kPa}$ in $0.20 \mathrm{~cm}$ soil depth, and between 0.4087 and $0.4578 \mathrm{kPa}$ in $5.0 \mathrm{~cm}$ soil depth.
\end{abstract}

Keywords: Deformation, stress, Poisson number, load, soil thickness.

(C) 2019 Türkiye Toprak Bilimi Derneği. Her Hakkı Saklıdır

\section{Giriş}

Reoloji özel bir bilim dalı olup, cisimlerin yük, şekil değiștirme ve zaman faktörleri altındaki gerilim, deformasyon, esneklik, genel akış vb. davranışlarını incelemektedir. Hidrodinamik, hidrolik, esneklik ve plastiklik teorisi, kesintisiz ortam mekaniği gibi bilim dalları da dolayısıyla reoloji teorisine dayanmaktadır (Burov ve Cloetingh, 1997; Qi ve Hou, 2006; Burov, 2011; Hart ve ark., 2011). Doğada bulunan tüm kristal yapıda masif kaya biçimindeki cisimler dış kuvvetlerin etkisi sonucunda pratik olarak toprağa dönüşebilmektedir. Bu nedenle, reoloji kurallarının aslında toprağa uygulanması mümkün gözükmektedir (Vyalov, 1986; Or ve Ghezzehei, 2002; Markgraf ve ark., 2006; Starovoitov ve Naghiyev, 2013). Toprak reolojisinde, zamanla gelişen ve tersi olmayan kalıntı deformasyonla ilişkili olan süreçlere (gerilme, sıkışma, parçalanma vb.) bakılmaktadır. Reolojik özelliklerin değişimi, bitki-kök sisteminin gelişiminde ve toprak

\footnotetext{
* Sorumlu yazar:

Tel. : $\quad 03263121919$

E-posta : iman@omu.edu.tr
}

Geliş Tarihi

Kabul Tarihi
21 Mayıs 2018

12 Nisan 2019
e-ISSN

DOI
2146-8141

$10.33409 /$ tbbbd.595142 
işlemede büyük öneme sahip olan fiziksel toprak özelliklerine de etki yapmaktadır. Optimum toprak işlemenin yapılması, gerilimin etkisiyle oluşan deformasyonun az olduğu anda mümkün olmaktadır.

Kısmen doymuş bir toprak bileşeni üzerindeki harici yüklerin bir sonucu olarak, iki toprak parçacığı arasındaki sıvı yerinden taşınır ve toprak parçacıkları arasındaki temas yüzey alanı artar. Artan temas yüzeyi alanı, toprak bileşenlerinin deformasyonuna bağlıdır. Metal malzemeler için belirlenen gerilmdeformasyon ilişkisi, toprak bileşenlerinin deformasyonunu tanımlayamaz. Metallar dışındaki diğer malzemeler için geliștirilmiş gerilim-deformasyon ilişkileri toprağa uygulanabilir (Prevost ve Höeg, 1975; Terzaghi ve ark., 1996, Richards, 2001). Toprağın reolojik özelliklerinin değișimi, toprak ișleme ve bitki kök sisteminin gelişiminde önemli faktör olan fiziksel özellikler üzerinde de etkilidir. Gerilim tarafından daha az deformasyon meydana geldiğinde optimum toprak işleme sürdürülebilir olarak yapılmaktadır. Toprak taşınım ve birikim süreçleri sonucunda toprak kalınlığı birikim sahalarında artmakta, gerilim, deformasyon vb. reolojik özellikler değişmektedir. Bu durum toprağın fiziksel özelliklerinin optimum düzeyde olmasına olumsuz yönde etki yapmaktadır. Toprak gerilimi besin maddesi, su ve tuz taşınımı gibi olaylar üzerinde de etkiye sahiptir.

Zemin mekaniğinde, özellikle toprakta reolojik özellikleri ifade eden denklemler iki çeşittir. Gerilim ve deformasyon arasındaki ilişkiyi ifade eden denklemlerin birinde zaman göz önüne alınmazken diğerinde alınmaktadır. Dolayısıyla ortam yüzeyine etki eden ve zamana göre çeșitli ilișkilerle ifade olunan kuvvet değişimi birinci çeşit denklemlerde kullanılmamaktadır (Koltunov ve ark. 1983).

$\mathrm{Bu}$ çalışmanın amacı, gerilim ve deformasyon arasındaki zamana bağlı olmayan denklemlerden elde edilecek analitik ifadeyle, toprakta farklı özgül ağırlık ve kalınlıklarda oluşabilecek yük değerleri için toprak geriliminin değerlendirilmesidir.

\section{Materyal ve Yöntem}

Topraktaki gerilim sürecinin nicel olarak değerlendirilmesi zamana bağlı olmayan gerilim-deformasyon denklemleriyle ilişkilidir. Bu denklemlerin kullanılmasında gerilim durumunun izotrop olması, toprağın $x, y, z$ koordinatları yönünde gerçekleşen üç temel gerilim $\left(\sigma_{1}, \sigma_{2}, \sigma_{3}\right)$ ve deformasyon $\left(\varepsilon_{1}, \varepsilon_{2}, \varepsilon_{3}\right)$ durumu göz önüne alınmaktadır. Gerilim-deformasyon denklemleri, toprak verileri (derinlik, özgül ağırlık), birikim sonucu meydana gelen yükün toprak yüzeyinde oluşturabileceği toprak gerilimini ifade etmek için elde edilen analitik ifade, bu çalışmanın materyallerini oluşturmaktadır. $\mathrm{Bu}$ analitik ifadenin oluşturulmasında matematiksel yaklaşım yöntemi kullanılmıştır (Ekberli, 2008).

\section{Katı Ortamda Gerilim ve Deformasyon}

Toprağın gerilim ve deformasyon durumu, toprak yüküne ve üzerine uygulanan mekaniksel kuvvetlere önemli düzeyde bağlıdır. Birim alandan geçen ve en küçük tanecikler (atomlar) arasındaki karşılıklı etki sonucunda yayılan kuvvet, ortamın gerilimini ifade etmektedir. Ortam yüzeyine dikey olarak etki eden kuvvet normal gerilim, yüzeye yatay olarak etki eden gerilim ise kayma olarak tanımlanmaktadır. Katmanlar üzerine olan normal gerilimlerin ortalama değerleri ise basıncı göstermektedir. Esnek (elastik) katı ortamda gerçekleşen gerilim ortamda deformasyon oluşturmaktadır. Katı ortamın başlangıç uzunluğunun uzunluk artışına oranı normal deformasyonu ifade etmektedir. Ortamda ayrılan dik açının deformasyon sonucunda azalmasının yarısı kayma (yersizme) deformasyonunu belirlemektedir. Esnek bir ortam olan toprağın yüzeyine dikey yönde etki yapan kuvvet gerilim oluşturmakta, dolayısıyla toprakta deformasyonu oluşmaktadır. Toprak yüzeyine uygulanan harici mekaniksel kuvvetler veya aşınan toprak kütlelerinin çukur sahalardaki toprak yüzeyinde birikimiyle oluşan yük miktarının artışı sonucunda da toprak yüzeyi sürekli olarak deformasyona uğramaktadır.

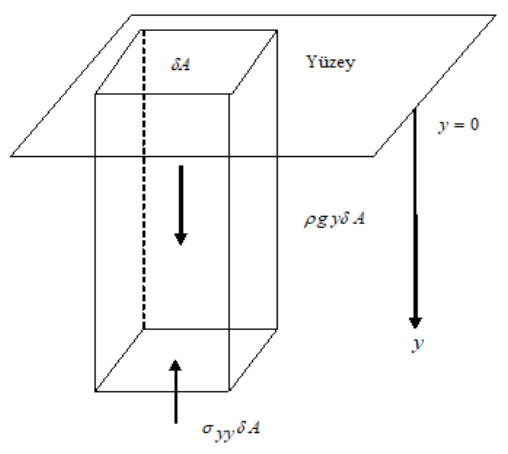

Şekil 1. Ortamın düşey sütununa etki eden ağırlık ve yüzeysel kuvveler 
Birim hacimde ağırlık kuvveti $\rho g$ ( $\rho$ - özgül ağırlık, $\mathrm{grcm}^{-3} ; g \approx 9.81 \mathrm{~m} \mathrm{sn}^{-2}$ - yerçekimi ivmesi) olarak, ortamın $y$ uzunluğunda, $\delta A$ alana sahip kesitindeki toplam ağırlık kuvveti $\rho g y \delta A$ olmaktadır (Şekil 1). Bu kuvvete eşit (dengeleyici) olan ters yöndeki yüzeysel kuvvet ise $\sigma_{y y} \delta A^{\prime}$ dır. Bu durumda, yan yönlerden dikey kuvvetlerin etki etmediği ve $\rho$ 'nın sabit olduğu varsayılmaktadır. Böylece, $\sigma_{y y}=\rho g y$ birim alanda yüzeye dikey olarak yönelen kuvvet olup, normal gerilimi (litostatik gerilimi veya basıncı) ifade etmektedir. $\mathrm{Bu}$ kuvvet derinlik boyunca doğrusal olarak artmaktadır. Katı ortamın gerilim ve deformasyon durumu, temel gerilim $\left(\sigma_{1}, \sigma_{2}, \sigma_{3}\right)$ ve deformasyon $\left(\varepsilon_{1}, \varepsilon_{2}, \varepsilon_{3}\right)$ değerlerine göre belirlenmektedir.

\section{Bulgular ve Tartışma}

\section{Katı Ortamda Gerilim ve Deformasyon Arasındaki Fonksiyonel İlişki}

Katı ortamın gerilimiyle deformasyonu doğrusal olarak bağıntılı, mekanik özellikleri ise yöne bağlı değilse, doğrusal ve izotrop olan esnek katı ortam oluşmaktadır. Bu ortamda gerilim ve deformasyonun temel eksenleri örtüşmektedir. Temel eksenlerle ilişkili olan koordinat sisteminde gerilim ve deformasyon arasındaki zamana bağlı olmayan bağıntı aşağıdaki gibidir (Turcotte ve Schubert, 1985):

$$
\begin{gathered}
\sigma_{1}=(\lambda+2 G) \varepsilon_{1}+\lambda \varepsilon_{2}+\lambda \varepsilon_{3} \\
\sigma_{2}=\lambda \varepsilon_{1}+(\lambda+2 G) \varepsilon_{2}+\lambda \varepsilon_{3} \\
\sigma_{3}=\lambda \varepsilon_{1}+\lambda \varepsilon_{2}+(\lambda+2 G) \varepsilon_{3}
\end{gathered}
$$

Burada, $\lambda$ ve $G$ ortamın esneklik modülleri veya Lame parametreleridir (aynı zamanda $G$ 'ye kayma mödülü (yersizme parametresi) de denilmektedir).

Ortamın doğrusal ve izotrop özelliğine göre, $\varepsilon$ deformasyonunun etkisi ile aynı yönde $(\lambda+2 G) \varepsilon$ gerilimi oluşmakta ve diğer iki $\lambda \varepsilon$ gerilimleri ise karşıllıklı dikey yönde olmaktadır.

$E=\frac{G(2 G+3 \lambda)}{G+\lambda}$ ve $v=\frac{\lambda}{2(G+\lambda)}$ olarak, (1) - (3) eşitliklerinden deformasyon öğeleri aşağıdaki gibi elde olunur:

$$
\begin{gathered}
\varepsilon_{1}=\frac{1}{E} \sigma_{1}-\frac{v}{E} \sigma_{2}-\frac{v}{E} \sigma_{3} \\
\varepsilon_{2}=-\frac{v}{E} \sigma_{1}+\frac{1}{E} \sigma_{2}-\frac{v}{E} \sigma_{3} \\
\varepsilon_{3}=-\frac{v}{E} \sigma_{1}-\frac{v}{E} \sigma_{2}+\frac{1}{E} \sigma_{3}
\end{gathered}
$$

Burada, $E$ vev ortamın (toprağın) esneklik özelliğini ifade etmekte, sirasıyla Young modülü (veya elastiklik modülü) ve Poisson sayısı olarak adlandırılmaktadır.

Young modülü toprağın kuvvet altında elastik biçimini değiştirme ölçüsünü, Poisson sayısı ise boyuna uzanma ile enine büzülme arasındaki oranın sabit olduğu değeri göstermektedir (Poulos ve Davis, 1974; Terzaghi ve ark., 1996). Bazı maddeler için $E, G$ ve $v$ değerleri Çizelge 1'de verilmiştir.

Çizelge 1. Bazı maddelerin esneklik değerleri

\begin{tabular}{lcccc}
\hline Madde & $\rho, \mathrm{gr} / \mathrm{cm}^{3}$ & $E, 10^{11} \mathrm{~Pa}$ & $G, 10^{11} \mathrm{~Pa}$ & $v$ \\
\hline Kil & $2.1-2.7$ & $0.1-0.3$ & 0.14 & $0.35-0.45$ \\
Kum & $2.2-2.7$ & $0.1-0.6$ & $0.04-0.30$ & $0.20-0.30$ \\
Kireç & $2.2-2.8$ & $0.6-0.8$ & $0.20-0.30$ & $0.25-0.30$ \\
Dolomit & $2.2-2.8$ & $0.5-0.9$ & $0.30-0.50$ & \\
Mermer & $2.2-2.8$ & $0.3-0.9$ & $0.20-0.35$ & $0.10-0.40$ \\
Bazalt & 2.95 & $0.6-0.8$ & 0.30 & 0.25 \\
Granit & 2.65 & $0.4-0.7$ & $0.20-0.30$ & $0.10-0.25$ \\
Buz & 0.9 & & 0.092 & 0.033 \\
\hline
\end{tabular}


Bir eksenli deformasyonda, deformasyon öğelerinin biri sıfırdan faklı olmaktadır. $\varepsilon_{1} \neq 0\left(\varepsilon_{2}=0\right.$ ve $\left.\varepsilon_{3}=0\right)$ olması durumunda gerilim ve deformasyon arasındaki ilişkiyi ifade eden (1) - (3) eşitliklerinden

$$
\begin{array}{r}
\sigma_{1}=(\lambda+2 G) \varepsilon_{1} \\
\sigma_{2}=\sigma_{3}=\lambda \varepsilon_{1}=\frac{\lambda}{\lambda+2 G} \sigma_{1}
\end{array}
$$

(4) - (6) eşitliklerinden ise

$$
\begin{gathered}
\sigma_{2}=\sigma_{3}=\frac{v}{1-v} \sigma_{1} \\
\sigma_{1}=\frac{(1-v) E \varepsilon_{1}}{(1+v)(1-2 v)}
\end{gathered}
$$

elde edilir.

(7) - (10) ifadelerini kullanarak, ortamın (toprağın) esneklik özelliğini ifade eden ve toprakların mekanik özelliklerinin değişiminin değerlendirilmesinde kullanılabilen $\lambda, G$ ve $v, E$ parametreleri arasındaki ilişkiler aşağıdaki gibi bulunur:

$$
\lambda=\frac{E v}{(1+v)(1-2 v)} ; \quad G=\frac{E}{2(1+v)} .
$$

\section{Farklı Yük Miktarları Altında Toprak Geriliminin Belirlenmesi}

Bir eksenli deformasyon denkleminin, bir biriyle ters süreçler olan aşınma ve çöküntü birikiminde kullanılması mümkündür (Jaeger ve Gook, 1976; Turcotte ve Schubert, 1985). Genel olarak deformasyon öncesi toprak yüzeyinin başlangıç gerilim durumu normal olmaktadır. Bu nedenle, toprağın $h$ derinliğinde temel gerilimler $\sigma_{1}=\sigma_{2}=\sigma_{3}=\rho g h$ gibi ifade edilir. Toprağın $h$ katmanındaki yük olmadığında ise yüzeydeki dikey gerilim $\bar{\sigma}_{1}=0$ olur. Bu durumda, dikey gerilimin değişimi $\Delta \sigma_{1}=\bar{\sigma}_{1}-\sigma_{1}=-\rho g h$ elde edilir. $\varepsilon_{2}=0$ ve $\varepsilon_{3}=0$ durumunda elde edilen (9) ifadesi aşağıdaki gibi olmaktadır:

$$
\Delta \sigma_{2}=\Delta \sigma_{3}=\frac{v}{1-v} \Delta \sigma_{1}=-\frac{v}{1-v} \rho g h .
$$

Bu durumda, düşey yüzeysel gerilim aşağıdaki biçimde ifade edilir:

$$
\bar{\sigma}_{2}=\bar{\sigma}_{3}=\sigma_{2}+\Delta \sigma_{2}=\rho g h-\frac{v}{1-v} \rho g h=\left(1-\frac{v}{1-v}\right) \rho g h=\frac{1-2 v}{1-v} \rho g h
$$

\begin{tabular}{|c|c|c|c|c|c|c|c|c|c|}
\hline \multirow{2}{*}{$\operatorname{gr} \stackrel{\rho,}{\mathrm{cm}}$} & \multicolumn{9}{|c|}{$h, c m$} \\
\hline & 0.2 & 0.4 & 0.6 & 0.8 & 1.0 & 2.0 & 3.0 & 4.0 & 5.0 \\
\hline & \multicolumn{9}{|c|}{ Kumlu toprak } \\
\hline 2.50 & 0,033 & 0,065 & 0,098 & 0,131 & 0,163 & 0,327 & 0,491 & 0,654 & 0,818 \\
\hline 2.65 & 0,035 & 0,069 & 0,104 & 0,139 & 0,173 & 0,347 & 0,520 & 0,693 & 0,867 \\
\hline \multirow[t]{2}{*}{2.80} & 0,037 & 0,073 & 0,110 & 0,147 & 0,183 & 0,366 & 0,544 & 0,733 & 0,916 \\
\hline & \multicolumn{9}{|c|}{ Killi toprak } \\
\hline 2.50 & 0,016 & 0,033 & 0,049 & 0,065 & 0,082 & 0,164 & 0,245 & 0,327 & 0,409 \\
\hline 2.65 & 0,017 & 0,035 & 0,052 & 0,069 & 0,087 & 0,173 & 0,260 & 0,347 & 0,433 \\
\hline 2.80 & 0,018 & 0,037 & 0,055 & 0,073 & 0,092 & 0,183 & 0,275 & 0,366 & 0,458 \\
\hline
\end{tabular}

Kum ve kil bünyeli toprak için sırasıyla $v=0.25$ ve $v=0.40$ değerleri kabul edildiğinde (Çizelge 1), toprağın farklı özgül ağırlık $(\rho)$ ve derinlikteki $(h)$ katmanlarında oluşacak yük altında, toprağın düşey yüzeysel gerilim değerleri (11) ifadesinden hesaplanarak Çizelge 2'de verilmiştir.

Çizelge 2. Farklı toprak kalınlıkları altında kumlu ve killi toprağın düşey yüzeysel gerilim değerleri ( $k P a)$

Toprağın düşey yüzeysel gerilimi özgül ağılık ve toprak derinliği ile doğru orantılı olarak artmaktadır. Toprağın Poisson sayısı ile gerilim değerleri ise ters yönde değişmektedir. Özgül ağırlı̆̆ın artışı, toprak 
derinliğinin artışı ile karşılaştırıldığında gerilimi daha az etkilediği görülmektedir. Toprak derinliği toprak yüzeyindeki yük miktarını etkilediğinden, gerilimin değișimi toprak derinliğinin değișiminden daha fazla etkilenmektedir. Toprak derinliğindeki artışa bağlı olarak $2.65 \mathrm{~g} \mathrm{~cm}^{-3}$ sabit özgül ağırlı̆̆a sahip farklı bünyeye sahip topraklarda gerilim miktarının $(\mathrm{kPa})$ değişimi Şekil 1'de verilmiştir. Aynı kalınlıktaki yük altında kil bünyeli topraklarda kum bünyeli topraklara göre daha fazla boşluk bulunduğundan, kil bünyeli topraklarda kum bünyeli topraklara göre daha az gerilim oluşmaktadır. Aynı özgül ağırlığa sahip kum bünyeli topraklarda toplam boşluk miktarının azalması yüzeyde oluşacak yükün kütlesindeki artışa bağlı olarak toprakta daha fazla bir boyutlu gerileme neden olmaktadır.

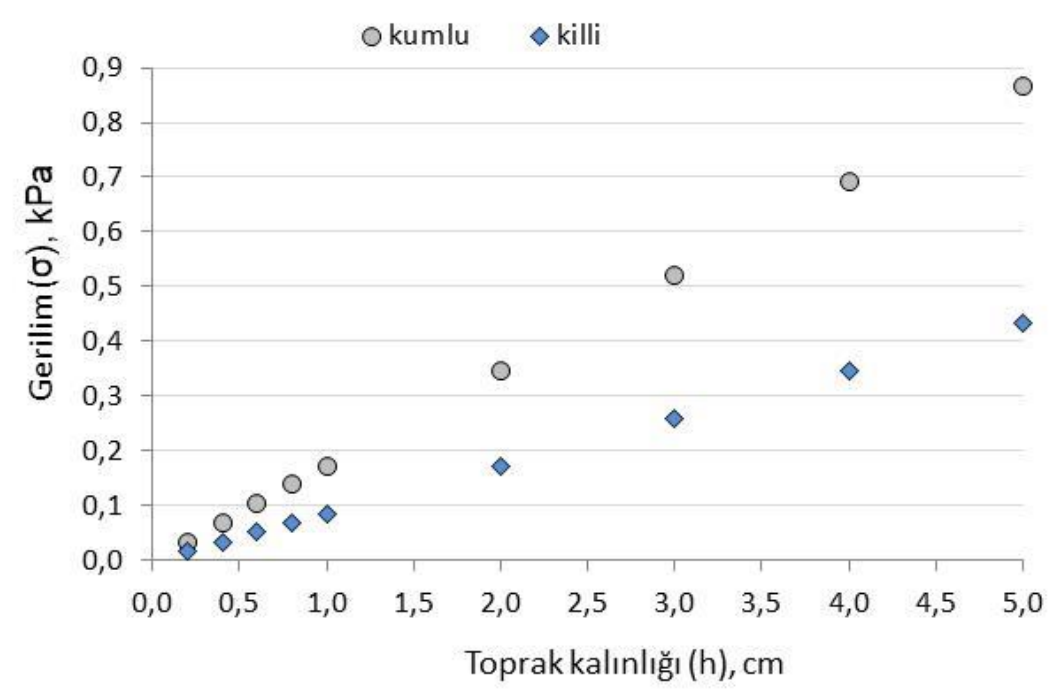

Şekil 1. Toprak kalınlığına bağlı olarak farklı bünyeli topraklarda gerilimin değişimi $\left(\rho=2.65 \mathrm{~g} \mathrm{~cm}^{-3}\right)$.

Toprak yüzeyindeki yüke bağlı oluşan gerilim, toprağın esnekliğine neden olmakta ve toprağın strüktürmekanik özelliklerine de negatif etki yapmaktadır. Aynı zamanda, gerilimin etkisi sonucunda toprak zerrecikleri arasındaki mesafe değişmekte ve deformasyon oluşmaktadır. Toprak derinliğindeki artışa bağlı olarak $2.65 \mathrm{~g} \mathrm{~cm}^{-3}$ sabit özgül ağırlığa sahip farklı bünyeye sahip topraklarda oluşan deformasyon değişimi eşitlik 10 yardımıyla hesaplanmış ve Şekil 2'de verilmiştir. Kil bünyeli topraklarda toprak yüzeyindeki yük kalınlığı arttıkça oluşan deformasyon miktarı kum bünyeli topraklara göre daha fazla olmaktadır.

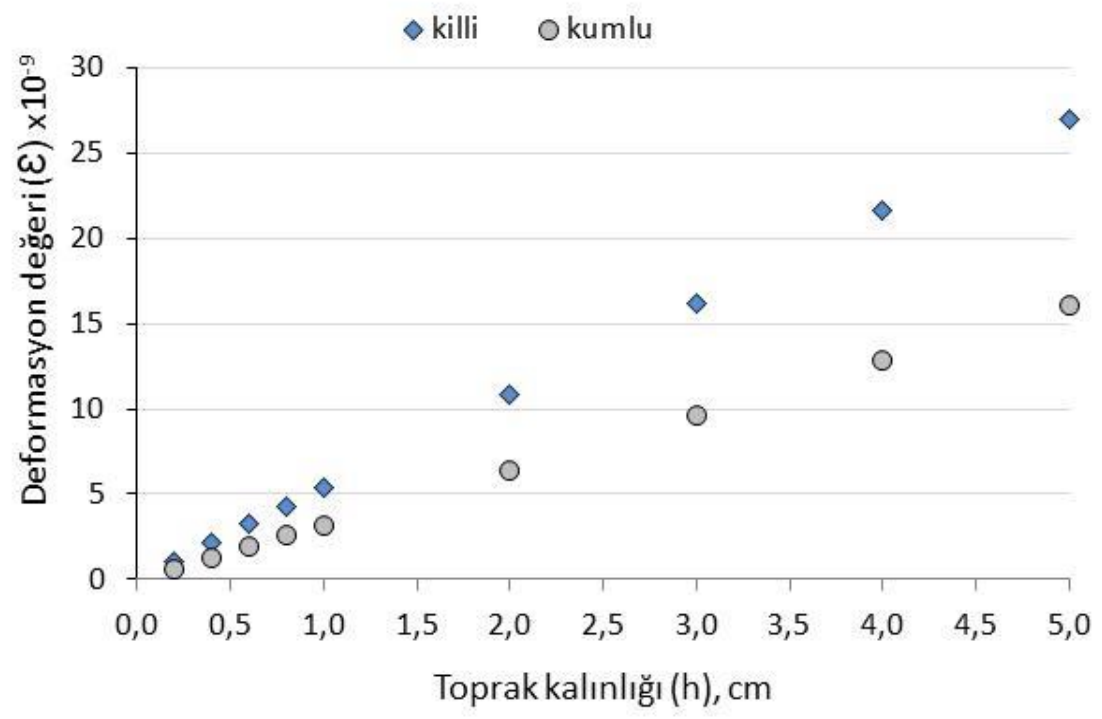

Şekil 2. Toprak kalınlığına bağlı olarak farklı bünyeli topraklarda deformasyonun değişimi $\left(\rho=2.65 \mathrm{~g} \mathrm{~cm}^{-3}\right)$.

Toprak sıcaklığı ve nemi de gerilim-deformasyon düzeyine önemli düzeyde etki yapmaktadır. Toprağın hacimsel deformasyonu, azalan hacim büyüklüğünde artan gözenek suyu basıncına bağlı olarak toprak su ile doyduğunda özellikle tehlikeli olabilir. Toprak zerreciklerine yukarı yönde etki eden kuvvet, yerçekimi tarafından aşağı yönde oluşan kuvvetten daha küçük ise, toprak zerreciklerinin taşınma tehlikesi 
bulunmamaktadır (Verruijt, 2012). Bu nedenle, toprak yüzeyindeki kayma gerilmesi, toprak zerrecikleri üzerinde etkili olan yerçekimi kuvvetinden daha büyükse, özellikle doymuş koşullarda toprak kaybı meydana gelebilir. Bu konunun daha da geliştirilmesi için, toprakta gerilim süreçlerine etki yapan diğer faktörlerin göz önüne alınması; konuyla ilgili çeşitli toprak işleme, rutubet, sıcaklık ve toprak özelliklerinde arazi çalışmalarının yapılması gerekmektedir. Araştırma deneysel ve teorik bilgilere bağlı olduğundan farklı disiplinlerin bir araya gelmesi konun aydınlatılması bakımından önemlidir.

\section{Kaynaklar}

Burov EB, 2011. Rheology and strength of the lithosphere. Marine and Petroleum Geology 28:1402-1443.

Burov E, Cloetingh C, 1997. Erosion and rift dynamics: new thermomechanical post-rift evolution of extensional basins. Earth and Planetary Science Letters 150: 7-26.

Ekberli İ, 2008. Sistemli yaklaşımla ekosistemin analizinde matematiksel modelleme yöntemi. Ondokuz Mayıs Üniversitesi Ziraat fakültesinin Dergisi 23(3):170-182.

Hart JK, Rose KC, Martinez K, 2011. Subglacial till behaviour derived from in situ wireless multi-sensor subglacial probes: Rheology, hydro-mechanical interactions and till formation. Quaternary Science Reviews 30: 234-247.

Jaeger JG, Gook NGW, 1976. Fundamentals of rock mechanics. London: Ghapman and Hall, 585 p.

Koltunov MA, Kravchuk AS, Majboroda VP, 1983. Applied mechanics of deformable solid body. Press Vysshaja Shkola, Moscow (in Russian), $349 \mathrm{p}$.

Markgraf W, Horn R, Peth S, 2006. An approach to rheometry in soil mechanics-Structural changes in bentonite, clayey and silty soils. Soil \& Tillage Research 91: 1-14.

Or D, Ghezzehei TA, 2002. Modeling post-tillage soil structural dynamics: a review. Soil \& Tillage Research 64: 41-59.

Poulos HG, Davis EH, 1974. Elastic solutions for soil and rock mechanics. New York, John Wiley and Sons, 411 p.

Prevost JH, Höeg K, 1975. Soil mechanics and plasticity analysis of strain softening. Geotechique 25 (2): 279-297.

Richards R, 2001. Principles of solid mechanics. CRC Press LLC, USA, 446 p.

Starovoitov E, Naghiyev FB, 2013. Foundations of the theory of elasticity, plasticity, and viscoelasticit. Apple Academic Press, Toronto, $364 \mathrm{p}$.

Qi P, Hou YJ, 2006. Mud mass transport due to waves based on an empirical rheology model featured by hysteresis loop. Ocean Engineering 33: 2195-2208.

Terzaghi K, Peck, RB, Mersi G, 1996. Soil mechanics in engineering practice. John Wiley Sons, Inc. New York, 549 p.

Turcotte DL, Schubert G, 1985. Geodynamics. Applications of Continuum Physics to Geological Problems, Volume 1, Press Mir, Moskow (in Russian), pp. 121-218.

Verruijt A, 2012. Soil mechanics. Delft University of Technology, Netherlands, 331 p.

Vyalov SS, 1986. Rheological fundamentals of soil mechanics. Elsevier, Amsterdam, 565 p. 